\title{
Relationship of Parent's Knowledge About Toilet Training with the Ability of 1 - 5 Years Agency in Conducting Toilet Training in the Ibnu Sina Kids, Pekanbaru City
}

\author{
Magdalena', Melly² \\ Poltekkes Kemenkes Riau \\ Emailmellykamal28@gmail.com
}

Article Info
Article history
Received date: 2019-11-19
Revised date: 2019-1 1-27
Accepted date: 2019-1 1-28

\begin{abstract}
In Indonesia it is estimated that the number of children under five reaches $30 \%$ of the 250 million inhabitants of Indonesia. According to the 2012 National Household Health survey the number of children under five who have difficulty controlling $B A B$ and BAK at the age of up to preschool reaches 75 million children. According to the Child Health Research Base (Riskesdas, 2010), it is estimated that the number of toddlers who have difficulty controlling BAB and BAK as well as defecated and defecated places until preschool age reaches $46 \%$ of children under five in Indonesia. This phenomenon is triggered because of many things, namely the lack of parental knowledge about how to practice bowel and urination during toddler age, use of diapers or disposable diapers. Lack of the role of parents in educating children to do toilet training and the habits of parents who allow children to defecate and urinate in any place (Firdaus \& Rahayu, 2013. The purpose of this study was to determine the relationship of parental knowledge about Toilet Training with the ability of children aged 1-5 Years in conducting Toilet Training at Ibnu Sina Kids Kindergarten Pekanbaru City This study used a cross sectional method. The population in this study were parents who had children aged $1-5$ years with a sample of 30. Univariate results showed the parents' knowledge of children aged 1 5 years at lbnu Sina Kids Kindergarten namely Good knowledge as many as 19 people $(63.3 \%)$, and the ability of children aged $1-5$ Years at Ibnu Sina Kids Kindergarten in conducting Toilet Training ie not independent as many as 18 children $(60.0 \%)$. Bivariate results show that there is a significant relationship between parents' knowledge and the ability of children aged 1 - 5 years in toileting tr aining, the statistical test results show ( $P$ Value $=0.018$ ). Mothers need to be equipped with knowledge and skills in order to understand in teaching children, especially elimination exercises, so that they can be positive in guiding the child's growth and development properly.
\end{abstract}

\section{Keywords:}

Children's Ability, Knowledge, Toilet Training

\begin{abstract}
Abstrak
Di Indonesia diperkirakan jumlah balita mencapai 30\% dari 250 juta jiwa penduduk Indonesia. Menurut survei Kesehatan Rumah Tangga Nasional tahun 2012 jumlah balita yang susah mengontrol BAB dan BAK di usia sampai prasekolah mencapai 75 juta anak, Menurut Riset Kesehatan Dasar Anak (Riskesdas, 2010), diperkirakan jumlah balita yang susah mengontrol $B A B$ dan $B A K$ serta $B A B$ dan $B A K$ disembarang tempat sampai usia prasekolah mencapai $46 \%$ anak dari jumlah balita yang ada di Indonesia. Fenomena ini dipicu karena banyak hal yaitu pengetahuan orang tua yang kurang tentang cara melatih BAB dan BAK pada saat anak usia toddler, pemakaian diapers atau popok sekali pakai. Tujuan penelitian ini adalah untuk mengetahui hubungan pengetahuan orang tua tentang Toilet Training
\end{abstract}


dengan kemampuan anak usia 1 - 5 Tahun dalam melakukan Toilet Training di TK Ibnu Sina Kids Kota Pekanbaru. Penelitian ini menggunakan metode cross sectional. Populasi pada penelitian ini adalah orang tua yang mempunyai anak usia 1-5 tahun dengan jumlah sampel 30 orang. Hasil univariat menunjukkan Pengetahuan orang tua anak usia $1-5$ Tahun di TK Ibnu Sina Kids yaitu pengetahuan Baik sebanyak 19 orang (63.3\%), dan kemampuan anak usia 1 - 5 Tahun di TK Ibnu Sina Kids dalam melakukan Toilet Training yaitu tidak mandiri sebanyak 18 orang anak $(60,0 \%)$. Hasil bivariat menunjukkan ada hubungan yang signifikan antara pengetahuan orang tua dengan kemampuan anak usia 1 - 5 Tahun dalam melakukan toilet training, hasil uji statistik menunjukkan $(P$ Value $=0,018)$. Ibu perlu dibekali pengetahuan dan keterampilan agar mengerti dalam mengajari anak khususnya latihan eliminasi, sehingga dapat bersikap positif dalam membimbing tumbuh kembang anak secara baik.

Kata Kunci

Kemampuan Anak, Pengetahuan, Toilet Training

\section{PENDAHULUAN}

Toilet training merupakan salah satu tugas utama anak pada usia toddler (anak usia 1 3 tahun). Anak harus mampu mengenali rasa untuk mengeluarkan dan menahan eliminasi serta mampu mengkomunikasikan sensasi $B A B$ dan $B A K$ kepada orang tua (Alexandra, 2008) dalam (Musfiroh dan Wisudaningtyas, 2014). Toilet training pada anak merupakan suatu usaha untuk melatih anak agar mampu mengontrol dalam melakukan buang air kecil atau buang air besar. Dalam melakukan toilet training, anak membutuhkan persiapan fisik, psikologis maupun intelektualnya. Dari persiapan tersebut diharapkan anak mampu mengontrol buang air besar atau buang air kecil secara mandiri '.

Anak usia 1-3 tahun menghadapi konflik antara tuntutan orang tua dengan keinginan dan kemampuan fisik anak. Orang tua menuntut anak untuk mampu menahan atau mengendalikan keinginan $B A B$ dan $B A K$, serta menginginkan anaknya melakukan $B A B$ dan BAK pada tempatnya, sementara anak ingin mengeluarkan begitu terasa ingin $B A B$ dan $B A K{ }^{2}$ dalam ${ }^{3}$.

Latihan untuk buang air besar dan buang air kecil adalah tugas perkembangan anak usia toddler. Pada tahapan usia 1-3 tahun, kemampuan sfingter uretra untuk mengontrol rasa ingin berkemih dan sfingter ani untuk mengontrol rasa defekasi mulai berkembang. Menurut 4 dalam Supartini (2012) mengemukakan bahwa biasanya sejalan dengan anak mampu berjalan, kedua sfingter tersebut semakin mampu mengontrol rasa ingin $B A B$ dan BAK. Setiap anak mempunyai perbedaan dalam kemampuan mengontrol rasa ingin berkemih dan defekasi, hal ini dipengaruhi oleh beberapa faktor baik fisik maupun psikologis.

Menurut Riset Kesehatan Dasar Anak (2010), diperkirakan jumlah balita yang susah mengontrol $B A B$ dan $B A K$ sampai usia prasekolah mencapai $46 \%$ anak dari jumlah balita yang ada di Indonesia. Fenomena ini dipicu karena banyak hal yaitu pengetahuan orang tua yang kurang tentang cara melatih $B A B$ dan $B A K$ pada saat anak usia toddler, pemakaian diapers atau popok sekali pakai. Kurangnya peran orang tua dalam mendidik anak untuk melakukan toilet training dan adanya kebiasaan orang tua yang membiarkan anak $B A B$ dan $B A K$ di sembarang tempat ${ }^{6}$. Berdasarkan Penelitian yang dilakukan oleh Lara \& Sakti (2013) ${ }^{11}$ di Paud Tunas Kelapa Desa Tungkaran menyebutkan jumlah anak usia toddler (1-3 tahun) sebanyak 35 anak dan sekitar 10 (25\%) anak yang sudah melakukan toilet training dan 25 (75\%) anak belum melakukan toilet training. Dari data tersebut dapat diketahui masih banyak anak yang harus mendapatkan 
perhatian khusus karena tugas perkembangan belum tercapai.

Kebiasaan yang salah dalam mengontrol $B A B$ dan BAK akan menimbulkan hal-hal yang buruk pada anak dimasa mendatang. Menyebabkan anak tidak disiplin, manja, dan yang terpenting adalah dimana nanti pada saatnya anak akan mengalami masalah psikologi, anak akan merasa berbeda dan tidak dapat secara mandiri mengontrol buang air besar dan buang air kecil ${ }^{7}$.

Dampak yang paling umum dalam kegagalan toilet training yaitu dapat menggangu kepribadian anak atau anak cenderung bersifat retentif, dimana anak cenderung bersikap keras kepala bahkan kikir dan emosional, hal ini terjadi karena adanya perlakuan atau aturan orang tua yang ketat kepada anak dan orang tua masih sering marah atau bahkan memberikan hukuman saat anaknya buang air besar atau buang air kecil disembarang tempat ${ }^{1}$.

Toilet training yang tidak diajarkan sejak dini akan membuat orang tua semakin sulit untuk mengajarkan ketika anak bertambah usianya, dan apabila orang tua juga santai dalam memberikan aturan dalam toilet training maka anak akan dapat mengalami gangguan kepribadian ekspresif yaitu anak akan cenderung diam, cenderung ceroboh dan seenaknya dalam kegiatan sehari-hari, selain itu anak tidak mandiri dan masih membawa kebiasaan mengompol hingga besar $^{1}$.

Studi pendahuluan yang dilakukan di Ibnu Sina Kids Kota Pekanbaru di dapatkan hasil anak usia toddler yang masih menggunakan pampers dan masih ditemani ke toilet sebanyak 22 orang anak dengan persentase $63 \%$ dari 35 orang anak dan masih banyak anak yang takut untuk buang air besar dan air kecil sendiri ke toilet. Dari hasil wawancara 11 orang tua yang mempunyai anak usia 1-5 tahun, 6 orang tua diantaranya masih belum mengetahui umur berapa anak mulai di ajarkan untuk melakukan toilet training.
Berdasarkan latar belakang di atas peneliti tertarik untuk meneliti "Hubungan pengetahuan orang tua tentang toilet training dengan kemampuan anak usia 1-5 Tahun dalam melakukan toilet training di Ibnu Sina Kids Kota Pekanbaru tahun 2019".

\section{METODE}

Penelitian ini merupakan penelitian deskriptif analitik dengan pendekatan cross sectional yaitu peneliti mencari hubungan antara variabel bebas (pengetahuan ibu tentang toilet training) dengan variabel terikat (kemampuan anak usia $1-5$ Tahun dalam melakukan toilet training) dengan melakukan observasi atau pengukuran pada satu saat tertentu. Kata satu saat bukan berarti semua subjek diamati tepat pada saat yang sama, tetapi artinya tiap subjek hanya diobservasi satu kali dan pengukuran variabel subjek dilakukan pada saat pemeriksaan tersebut ${ }^{8}$.

Populasi pada penelitian ini adalah semua orang tua dan anak usia 1-5 tahun di TK Ibnu Sina Kids Kota Pekanbaru tahun 2019. Sampel penelitian adalah sebagian dari keseluruhan objek yang diteliti dan dianggap mewakili seluruh populasi?. Dalam pengambilan sampel, penelitian ini menggunakan teknik total sampling yaitu seluruh populasi yang ada, dimana sampel pada penelitian ini yaitu orang tua dan anak usia 1-5 tahun sebanyak 30 orang di TK Ibnu Sina Kids Kota Pekanbaru tahun 2019, Teknik Pengumpulan data dilakukan dengan cara penyebaran kuesioner kepada responden yang disebarkan langsung oleh peneliti dan dengan mengisi lembar observasi oleh peneliti dan Setelah data diperoleh maka dilakukan pengolahan data dengan menggunakan sistem computerisasi analisa data menggunakan analisa univariat dan bivariat

\section{HASIL DAN PEMBAHASAN}

Hasil

Analisa Univariat 


\section{Umur}

\section{Tabel 1}

Distribusi Frekuensi Responden Berdasarkan Umur Orang Tua Anak Usia $1-5$ Tahun di TK Ibnu Sina Kids Kota Pekanbaru tahun 2019

\begin{tabular}{cccc}
\hline No & $\begin{array}{c}\text { Klasifikasi } \\
\text { Umur }\end{array}$ & Jumlah & $(\%)$ \\
\hline 1 & $21-30$ & 24 & 80 \\
\hline 2 & $31-40$ & 6 & 20 \\
\hline & Jumlah & 30 & 100 \\
\hline
\end{tabular}

Tabel 1 menunjukkan bahwa mayoritas umur orang tua anak di TK Ibnu Sina Kids Kota Pekanbaru tahun 2019 adalah berumur 24-30 tahun sebanyak 24 orang $(80 \%)$.

\section{Pekerjaan}

Tabel 2

Distribusi Frekuensi Responden Berdasarkan Pekerjaan Orang Tua Anak Usia 1 - 5 Tahun di TK lbnu Sina Kids Kota Pekanbaru tahun 2019

\begin{tabular}{cccc}
\hline No & Pekerjaan & Jumlah & $(\%)$ \\
\hline 1 & IRT & 6 & 20.0 \\
\hline 2 & PNS & 7 & 23.3 \\
\hline 3 & Swasta & 12 & 40 \\
\hline 4 & Wiraswasta & 5 & 16.7 \\
\hline & Jumlah & 30 & 100 \\
\hline
\end{tabular}

Tabel 2 menunjukkan bahwa mayoritas pekerjaan orang tua anak di TK Ibnu Sina Kids Kota Pekanbaru tahun 2019 adalah swasta sebanyak 12 orang $(40 \%)$.

\section{Pendidikan}

\section{Tabel 3}

Distribusi Frekuensi Responden Berdasarkan Pendidikan Orang Tua Anak di TK Ibnu Sina Kids Kota Pekanbaru tahun 2019

\begin{tabular}{cccc}
\hline No & Pendidikan & Jumlah & $(\%)$ \\
\hline 1 & Sarjana & 14 & 46.7 \\
\hline 2 & SMA & 15 & 50 \\
\hline 3 & SMP & 1 & 3.3 \\
\hline
\end{tabular}

\begin{tabular}{lll}
\hline Jumlah & 30 & 100 \\
\hline
\end{tabular}

Tabel 3 menunjukkan bahwa mayoritas pendidikan orang tua di TK Ibnu Sina Kids Kota Pekanbaru tahun 2019 adalah SMA sebanyak 15 orang (50\%).

\section{Pengetahuan}

Tabel 4

Distribusi Frekuensi Responden Berdasarkan Pengetahuan Orang Tua Anak di TK Ibnu Sina Kids Kota Pekanbaru tahun 2019

\begin{tabular}{cccc}
\hline No & Pengetahuan & Jumlah & $(\%)$ \\
\hline 1 & Kurang Baik & 11 & 36.7 \\
\hline 2 & Baik & 19 & 63.3 \\
\hline & Jumlah & 30 & 100
\end{tabular}

Tabel 4 menunjukkan bahwa mayoritas pengetahuan orang tua di TK Ibnu Sina Kids Kota Pekanbaru tahun 2019 adalah berpengetahuan baik sebanyak 19 orang (63.3\%).

\section{Kemampuan}

Tabel 5

Distribusi Frekuensi Responden Berdasarkan Kemampuan Anak di TK Ibnu Sina Kids Kota Pekanbaru Tahun 2019

\begin{tabular}{cccc}
\hline No & $\begin{array}{c}\text { Kemampuan } \\
\text { Anak }\end{array}$ & Jumlah & $(\%)$ \\
\hline 1 & Tidak Mandiri & 18 & 60 \\
\hline 2 & Mandiri & 12 & 40 \\
\hline & Jumlah & 30 & $100 \%$ \\
\hline
\end{tabular}

Tabel 5 menunjukkan bahwa mayoritas Kemampuan Anak Usia 1 - 5 Tahun melakukan Toilet training di TK Ibnu Sina Kids Kota Pekanbaru tahun 2019 adalah Tidak Mandiri sebanyak 18 orang $(60,0 \%)$. 


\section{Analisa Bivariat}

Tabel 6

Hubungan Pengetahuan Orang Tua Tentang Toilet Training Dengan Kemampuan Anak Usia $1-5$ Tahun Melakukan Toilet Training di TK Ibnu Sina Kids Kota Pekanbaru Tahun 2019

\begin{tabular}{|c|c|c|c|c|c|c|c|c|}
\hline \multirow[t]{3}{*}{ Pengetahuan } & \multicolumn{3}{|c|}{ Kemampuan } & \multicolumn{2}{|c|}{ Total } & \multirow[t]{3}{*}{ P Value } & \multirow{2}{*}{\multicolumn{2}{|c|}{ OR }} \\
\hline & \multicolumn{2}{|c|}{ Tidak Mandiri } & \multirow{2}{*}{$\begin{array}{c}\text { Mandiri } \\
\mathrm{F}\end{array}$} & & & & & \\
\hline & $\mathrm{F}$ & $\%$ & & $\%$ & $F$ & & & \\
\hline Kurang Baik & 10 & 90.9 & 1 & 9.1 & 10 & 100 & & \\
\hline Baik & 8 & 42.1 & 11 & 57.9 & 19 & 100 & 0.018 & 14 \\
\hline Total & 18 & 60 & 12 & 40 & 30 & 100 & & \\
\hline
\end{tabular}

Tabel 6 menunjukkan bahwa orang tua yang mempunyai pengetahuan baik tentang toilet training di TK Ibnu Sina Kids Kota Pekanbaru tahun 2019 memiliki kemampuan anak usia 1-5 tahun yang mandiri melakukan toilet training adalah sebanyak 11 orang $(57.9 \%)$, sedangkan orang tua yang mempunyai pengetahuan kurang baik tentang toilet training memiliki kemampuan anak usia $1-5$ tahun yang tidak mandiri melakukan toilet training sebanyak 1 orang (9.1\%).

Berdasarkan hasil uji statistic maka peneliti menggunakan uji Fisher Exact Test diperoleh nilai $p$ value sebesar 0.018 ( $p$ value $<0.05$ ). Maka dapat diambil kesimpulan bahwa ada hubungan yang signifikan antara pengetahuan orang tua tentang toilet training dengan kemampuan anak usia 1-5 tahun melakukan toilet training di TK Ibnu Sina Kids Kota Pekanbaru tahun 2019. Kemudian dari hasil analisis diperoleh OR = 14 artinya pengetahuan orang tua tentang toilet training yang kurang baik mempunyai resiko 14 kali anaknya yang berusia 1-5 tahun tidak mandiri dalam melakukan toilet training dibandingkan dengan pengetahuan orang tua yang baik.

\section{Pembahasan}

1. Umur

Distribusi frekuensi umur orang tua anak usia 1-5 Tahun di TK Ibnu Sina Kids Kota Pekanbaru diperoleh pada kuesioner yang dikumpulkan dari 30 orang responden. Pada penelitian ini diketahui bahwa mayoritas orang tua anak usia 1 - 5 Tahun di TK Ibnu Sina Kids adalah berumur 21-30 tahun sebanyak 24 orang ( $80 \%$ ).

Umur adalah usia individu yang terhitung mulai saat dilahirkan sampai berulang tahun. Semakin cukup umur maka tingkat kematangan dan kekuatan seseorang akan lebih matang dalam berfikir dan bekerja Huclock (1998) ${ }^{10}$. Usia 21-30 tahun merupakan kelompok umur ibu yang telah mencapai kematangan dalam mengasuh dan membimbing anaknya. Bertambahnya usia seseorang dapat berpengaruh pada pengetahuan yang diperolehnya. Hubungan umur dengan tingkat kematangan ibu dikemukakan oleh Nurjanah (2001) 7, lbu dengan usia antara 20 tahun hingga 35 tahun merupakan ibu dalam kelompok umur produktif, dimana mereka telah memiliki kematangan dalam hal rasional dan motorik, sehingga mereka mampu mengetahui cara-cara pengasuhan anak yang baik dan mampu mempraktekannya dalam bentuk pengasuhan anak yang baik. Kematangan dan pengalaman ibu dalam pengasuhan anak, diantaranya adalah dengan mengajarkan toilet training kepada anaknya sehingga anak akan mandiri pada saat melakukan toilet training. 


\section{Pekerjaan}

Distribusi frekuensi mayoritas pekerjaan orang tua anak usia 1-5 tahun di TK Ibnu Sina Kids Kota Pekanbaru diperoleh pada kuesioner yang dikumpulkan dari 30 orang responden. Pada penelitian ini diketahui bahwa mayoritas orang tua anak usia $1-5$ tahun di TK Ibnu Sina Kids Kota Pekanbaru bekerja sebagai pekerja swasta sebanyak 12 orang $(40 \%)$.

Pekerjaan adalah sesuatu yang harus dilakukan terutama untuk menunjang kehidupan. Bekerja merupakan kegiatan yang menyita waktu. Bekerja bagi ibu-ibu akan mempunyai pengaruhi terhadap kehidupan keluarga ${ }^{10}$.

Jika dilihat dari status pekerjaan, sebagian besar responden bekerja sebagai pegawai swasta (40\%). Salah satu faktor pembentuk pengetahuan seseorang adalah lingkungan sosial termasuk di dalamnya lingkungan kerja. Akan tetapi, seiring dengan perkembangan teknologi informasi dan komunikasi khususnya yang berbasis internet, memudahkan seseorang untuk memperoleh informasi dan sumber pengetahuan up to date kapanpun dan dimanapun tanpa harus dibatasi oleh ruang dan waktu, sehingga ibu yang tidak bekerjapun dapat memperoleh informasi untuk meningkatkan pengetahuan.

\section{Pendidikan}

Pada penelitian ini diketahui bahwa mayoritas orang tua anak usia $1-5$ Tahun di TK Ibnu Sina Kids Kota Pekanbaru mempunyai Pendidikan SMA sebanyak 15 orang $(50 \%)$. Pendidikan berarti proses pembelajaran pengetahuan, keterampilan, dan kebiasaan sekumpulan manusia yang diwariskan dari satu genereasi ke generasi selanjutnya melalui pengajaran, pelatihan, dan penelitian.atau memberi bimbingan kepada seseorang terhadap perkembangan orang lain. Pendidikan di perlukan untuk mendapatkan informasi. Pada umumnya makin tinggi pendidikan seseoramg maka makin mudah menerima informasi 8,10 .
Menurut Erfandi (2009) pendidikan mempengaruhi proses belajar, semakin tinggi pendidikan seseorang maka semakin mudah orang tersebut untuk menerima informasi. Pendidikan yang diperoleh seseorang memiliki pengaruh pada peningkatan kemampuan berpikir dan bertindak, dengan kata lain seseorang yang berpendidikan lebih tinggi akan dapat mengambil keputusan yang lebih rasional, umumnya terbuka untuk menerima perubahan atau hal baru dibandingkan dengan individu yang berpendidikan lebih rendah. Seseorang dengan pendidikan menengah (SMA) telah memiliki dasardasar pengetahuan yang cukup sehingga mampu menyerap dan memahami pengetahuan dibandingkan dengan pendidikan dasar (SD dan SMP).

Tingkat pendidikan yang baik akan mempengaruhi tingkat pengetahuan dan sikap ibu dalam menerima dan memahami suatu informasi yang diberikan ketika menerima penyuluhan kesehatan, sebagaimana dikemukakan7, yang mengemukakan bahwa, status pendidikan mempengaruhi kesempatan memperoleh informasi. Distribusi responden menurut pendidikan menunjukkan sebagian besar responden berada pada tingkat pendidikan baik. Kondisi ini menyebabkan kemampuan responden untuk memahami tentang pemberian pengetahuan tentang toilet training pada anaknya menjadi baik.

\section{Pengetahuan}

Berdasarkan penelitian yang telah dilakukan, didapatkan hasil bahwa Pengetahuan orang tua anak usia $1-5$ Tahun di TK Ibnu Sina Kids Kota Pekanbaru yaitu kurang Baik sebanyak 11 orang $(36,7 \%)$ dan pengetahuan baik sebanyak 19 orang $(63,3 \%)$. Hal ini sejalan dengan penelitian Pusparini dan Arifah (2009) Pengetahuan tentang toilet training sangat penting untuk dimiliki oleh seorang ibu. $\mathrm{Hal}$ ini akan berpengaruh pada penerapan toilet training pada anak. lbu yang mempunyai tingkat pengetahuan yang baik 
berarti mempunyai pemahaman yang baik tentang manfaat dan dampak toilet training, sehingga ibu akan mempunyai sikap yang positif terhadap konsep toilet training ${ }^{7}$.

Mayoritas pengetahuan orang tua anak usia - 5 Tahun di TK Ibnu Sina Kids Kota Pekanbaru mempunyai pengetahuan baik. Pengetahuan ibu yang baik berdampak positif terhadap anak usia $1-5$ tahun untuk mempelajari toilet training. Hal ini terlihat pada hasil penelitian tingkat pengetahuan orang tua. Ada sebanyak 19 orang tua yang berpengetahuan baik, dan 11 orang tua yang berpengetahuan kurang baik.

Pengetahuan ibu tentang toilet training tersebut merupakan hasil dari tahu dan ini terjadi setelah orang melakukan penginderaan terhadap suatu objek tertentu. Pengetahuan ibu tentang toilet training berdampak pada pemahaman ibu tindakan yang seharusnya dilakukan dalam pemberian toilet training pada anaknya.

Ibu perlu dibekali pengetahuan dan keterampilan agar mengerti dan terampil dalam melaksanakan pengasuhan anak khususnya latihan eliminasi, sehingga dapat bersikap positif dalam membimbing tumbuh kembang anak secara baik 13 .

\section{Kemampuan Toilet Training}

Berdasarkan penelitian yang telah dilakukan, didapatkan hasil bahwa kemampuan anak usia $1-5$ tahun dalam melakukan toilet training di TK Ibnu Sina Kids Kota Pekanbaru yaitu tidak mandiri sebanyak 18 orang anak $(60,0 \%)$ dan kemampuan anak usia 1 - 5 tahun yang mandiri sebanyak 12 orang anak $(40,0 \%)$. mayoritas anak usia 1 - 5 dalam melakukan toilet training usia $1-5$ Tahun di TK Ibnu Sina Kids Kota Pekanbaru yaitu tidak mandiri. hal ini ini menunjukkan orang tua belum menerapkan toilet training dengan benar kepada anak. sebagian besar orang tua kurang mengetahui tentang penerapan toilet training, itu terlihat dari jawaban yang di berikan oleh orang tua kepada peneliti. Toilet training merupakan salah satu tugas utama anak pada usia toddler (anak usia 1 5 tahun). Anak harus mampu mengenali rasa untuk mengeluarkan dan menahan eliminasi serta mampu mengkomunikasikan sensasi $B A B$ dan $B A K$ kepada orang tua Alexandra, (2008) 3. Toilet training pada anak merupakan suatu usaha untuk melatih anak agar mampu mengontrol dalam melakukan buang air kecil atau buang air besar. Dalam melakukan toilet training, anak membutuhkan persiapan fisik, psikologis maupun intelektualnya. Dari persiapan tersebut diharapkan anak mampu mengontrol buang air besar atau buang air kecil secara mandiri ${ }^{1}$.

\section{Hubungan Pengetahuan Orang Tua Tentang Toilet training dengan Kemampuan Anak Usia 1 - 5 Tahun di TK Ibnu Sina Kids Kota Pekanbaru}

Berdasarkan hasil penelitian dengan uji statistic chi-square terdapat hubungan Pengetahuan Orang Tua Tentang Toilet training dengan Kemampuan Anak Usia 1 5 Tahun di TK Ibnu Sina Kids Kota Pekanbaru diperoleh nilai $p$ value sebesar 0,018 ( $p$ value $<0,05$ ). Hasil penelitian ini sejalan dengan penelitian Lara dan sakti, (2013) ${ }^{11}$ bahwa terdapat hubungan yang signifikan antara tingkat pengetahuan ibu dengan pelaksanaan toilet training secara mandiri pada anak usia 1-3 tahun. Mayoritas pengetahuan orang tua anak Usia 1 - 5 Tahun di TK Ibnu Sina Kids Kota Pekanbaru mempunyai pengetahuan baik. Sebagian besar orang tua mengetahui tentang penerapan toilet training. Hal ini terlihat pada hasil penelitian kemampuan anak usia $1-5$ tahun dalam melakukan toilet training ada sebanyak 18 orang anak $(60,0 \%)$ yang tidak mandiri sedangkan kemampuan anak 1 - 5 tahun yang Mandiri sebanyak 12 orang anak $(40,0 \%)$. Penelitian ini sejalan dengan penelitian Firdaus dan Rahayu (2013)6 bahwa uji chisquare yang dilakukan dengan nilai kemaknaan $\alpha=0,05$, didapatkan nilai signifikan $\rho=0,001<0,05$ yang berarti $\mathrm{HO}$ di tolak maka terdapat hubungan peran orang tua dengan kemampuan toilet training 
pada anak usia toddler di PAUD Permata Bunda RW 01 Desa Jati Selatan 1 Sidoarjo. Pengetahuan tentang toilet training sangat penting untuk dimiliki oleh seorang ibu. Hal ini akan berpengaruh pada penerapan toilet training pada anak. lbu yang mempunyai tingkat pengetahuan yang baik berarti mempunyai pemahaman yang baik tentang manfaat dan dampak toilet training, sehingga ibu akan mempunyai sikap yang positif terhadap konsep toilet training 7 . Penelitian yang dilakukan oleh Pusparini dan Arifah (2009) bahwa hipotesis nol ditolak dan secara statistik ada hubungan yang signifikan antara tingkat pengetahuan ibu tentang toilet training dengan perilaku ibu dalam melatih toilet training ${ }^{7}$.

Toilet training yang tidak diajarkan sejak dini akan membuat orang tua semakin sulit untuk mengajarkan ketika anak bertambah usianya, dan apabila orang tua juga santai dalam memberikan aturan dalam toilet training maka anak akan dapat mengalami gangguan kepribadian ekspresif yaitu anak akan cenderung diam, cenderung ceroboh dan seenaknya dalam kegiatan sehari-hari, selain itu anak tidak mandiri dan masih membawa kebiasaan mengompol hingga besar ${ }^{1}$.

Penelitian yang dilakukan Istiqomah, (2013) bahwa pengetahuan orang tua mempunyai hubungan dengan pelaksanaan toilet training untuk anak usia 24 bulan sampai dengan 41 bulan secara mandiri ${ }^{15}$. Berdasarkan pernyataan diatas peneliti menyimpulkan bahwa pengetahuan orang tua dapat mempengaruhi kemampuan anak usia 1 - 5 tahun dalam melakukan toilet training termasuk Pengetahuan tentang toilet training sangat penting untuk dimiliki oleh seorang ibu. Hal ini akan berpengaruh pada penerapan toilet training pada anak. Ibu yang mempunyai tingkat pengetahuan yang baik berarti mempunyai pemahaman yang baik tentang manfaat dan dampak toilet training, sehingga ibu akan mempunyai sikap yang positif terhadap konsep toilet training. Semakin baik pengetahuan orang tua maka semakin banyak anak yang Mandiri dalam melakukan toilet training.

\section{SIMPULAN}

berdasarkan penelitian yang telah dilakukan pada 30 orang tua dan anak usia 1-5 tahun. maka dapat diambil kesimpulan sebagai berikut:

Karakteristik Responden

a. Umur orang tua anak di TK Ibnu Sina Kids Kota Pekanbaru tahun 2019 adalah mayoritas berumur 24-30 tahun sebanyak 24 orang (80\%).

b. Pekerjaan orang tua anak di TK Ibnu Sina Kids Kota Pekanbaru tahun 2019 adalah Swasta sebanyak 12 orang $(40 \%)$.

c. Pendidikan orang tua anak di TK Ibnu Sina Kids Kota Pekanbaru tahun 2019 adalah SMA sebanyak 15 orang (50\%).

d. Pengetahuan orang tua anak Usia 1 5 Tahun di TK Ibnu Sina Kids Kota Pekanbaru tahun 2019 adalah mayoritas mempunyai pengetahuan baik sebanyak 19 orang (63.3\%).

e. Kemampuan anak usia 1 - 5 Tahun dalam melakukan toilet training di TK Ibnu Sina Kids Kota Pekanbaru mayoritas Tidak Mandiri sebanyak 18 orang $(60,0 \%)$.

f. Berdasarkan hasil uji statistik Fisher Exact Test terdapat hubungan antara pengetahuan orang tua tentang toilet training dengan kemampuan anak usia 1 - 5 Tahun dalam melakukan toilet training diperoleh nilai $p$ value sebesar 0,018 ( $p$ value < 0,05). Maka dapat diambil kesimpulan bahwa ada hubungan yang signifikan antara pengetahuan orang tua tentang toilet training dengan kemampuan anak usia 1 - 5 Tahun dalam melakukan toilet training. 


\section{UCAPAN TERIMA KASIH}

Pada kesempatan ini kami mengucapkan terima kasih kepada pihak-pihak yang telah membantu dalam pelaksanaan penelitian ini :

1. H. Husnan, S.Kp., MKM, selaku Direktur Poltekkes Kemenkes Riau.

2. Ibu Hi. Rusherina S.Pd., S.Kep., M.kes, selaku Ketua Jurusan Keperawatan Poltekkes Kemenkes Riau.

3. Wadir I, Wadir II, dan Wadir III Poltekkes Kemenkes Riau

4. Tim Pakar sebagai penguji dalam seminar hasil penelitian ini.

5. Kepala TK Ibnu Sina Kids Kota Pekanbaru

\section{DAFTAR PUSTAKA}

[1] Hidayat, A. (2008). Riset Keperawatan dan Teknik Penulisan Ilmiah.Jakarta : salemba Medika.

[3] Musfiroh, M \& Lukmanawati, B. 2014. Jurnal Kesehatan Masyarakat :Penyuluhan Terhadap Sikap lbu Dalam Memberikan Toilet Training Pada Anak. Diakses pada Rabu, 14 September 2016, 13.29.24

[4] Wong, D.L. Dkk. (2008). Buka Ajar Keperawatan Pediatrik. Jakarta: EGC

[5] Supartini, Y. (2012) .Buku Ajar Konsep Dasar Keperawatan Anak. Jakarta: EGC

[6] Firdaus \& Rahayu DM. (2013). Jurnal Hubungan Peran Orang Tua dengan Kemampuan Toilet Training pada Anak Usia Toddler. Di Akses Pada Rabu, 08Februari ,201723.37
[7] Pusparini, W \& Arifah, S. (2010). Jurnal Hubungan Pengetahuan lbu Tentang Toilet Training dengan Perilaku Ibu Dalam Melatih

[8] Notoatmodio, S. (2012). Promosi Kesehatan dan Ilmu Perilaku. Jakarta: Rineka Cipta.

[9] Setiadi. (2013). Konsep dan Praktik Penulisan Riset Keperawatan. Yogyakarta: Graha Ilmu.

[10] Wawan \& Dewi. (2010). Teori dan Pengukuran Pengetahuan, Sikap, Dan Perilaku Manusia. Yogyakarta : Nuha Medika

[11] Lara, R \& Sakti, R. (2013). Skripsi : Hubungan Antara Tingkat Pengetahuan lbu dengan Pelaksanaan Toilet Training Secara Mandiri Pada Anak Usia 1 - 3 Tahun Di Paud Tunas Kelapa Desa Tungkaran Pangeran Kabupaten Tanah Bumbu Tahun 2013. Diakses pada Rabu, 14 September 2016.

[12] Iryanti \& Kamsatun. (2015). Jurnal pengaruh Modul pemberdayaan keluarga tentang toilet training terhadap kemandirian Eliminasi anak di paud. Di akses pada Selasa, 13 September 2016.

[13] Istiqomah. (2013). Jurnal Hubungan Tingkat Pengetahuan Ibu Asuh dengan Pelaksanaan Toilet Training Secara Mandiri Pada Anak Usia Toddler Di Tpa Citra Rsu Rajawali Citra Bantul. Diakses pada Rabu, 3 mei 2017. 